\title{
PENANAMAN PENDIDIKAN MULTIKULTURAL DALAM MEMBENTUK AKHLAK SANTRI DI PONDOK PESANTREN NGALAH SENGONAGUNG
}

\author{
${ }^{1}$ Sifaul Jannah, ${ }^{2}$ Muhammad Nur Hadi \\ ${ }^{1}$ jannah@gmail.com, ${ }^{2}$ nurhadi@yudharta.ac.id \\ ${ }^{1}$ MTs. Capang Purwodadi, Pasuruan \\ ${ }^{2}$ Universitas Yudharta Pasuruan
}

\begin{abstract}
This research is motivated by the diversity of Indonesia's multicultural, ethnic and religious communities, as well as multiculturalism. Islamic education that touches on the aspect of morality is Islamic boarding schools. Islamic boarding schools are institutions that istiqamah still maintain the tradition of peace, balance and harmony and continue to develop the principle $\mathrm{s}$ of ukhuwahIslamiyah, wathaniyah, and basyariyah in an effort to strengthen the Unitary Republic of Indonesia (NKRI). This type of research is qualitative phenomenological field research. The data in this study consisted of primary data and secondary data. While the technique of collecting data through $\{a\}$ observation, $\{b\}$ interview, and $\{c\}$ documentation. To test the credibility of the data the author uses the data source triangulation technique. Then the data analysis is carried out at the beginning of the research to the conclusion. From the results of the research conducted, it can be concluded that: first, the principle of planting multicultural education in the Ngalah Islamic boarding school is rahmatanlil'alamin \{protector for all circles\}. Second, the implementation of planting multicultural education in the Islamic boarding school Ngalahala NU which includes 3 morals, namely Wathaniyah \{Polite towards the State\}, Insaniyah \{Compassionate towards fellow human beings\}, and Islamiyah \{polite to fellow Muslims $\}$ and cling to the Pancasila and the 1945 Constitution, through habituation of attitudes, among others: a) Religious (religious), b) Humanist (humanity), c) Nationalist, d) democracye)tolerance with exemplary media caregiver, orientation of new santri, ta'lim ad diniyah, dormitory life, stage art and halaqoh. It was proven by the enthusiasm and istiqomah attitude of the santri in participating in the pesantren activities that had been scheduled starting daily, weekly, monthly and yearly.
\end{abstract}

Keywords: planting, multicultural education 
Pondok Pesantren Ngalah Sengonagung.

Abstrak: Penelitian ini dilatarbelakangi oleh adanya keberagaman masyarakat Indonesia yang multisuku, etnik dan agama, serta multibudaya. Pesantren merupakan lembaga yang secara istiqamah tetap mempertahankan tradisi kedamaian, keseimbangan, dan keharmonisan dan tetap mengembangkan prinsip ukhuwah Islamiyah, wathaniyah, dan basyariyah dalam upaya memperkuat Negara Kesatuan Republik Indonesia (NKRI). Jenis penelitian ini adalah penelitian lapangan yang bersifat kualitatif fenomenologi. Data dalam penelitian ini terdiri dari data primer dan data skunder. Sedangkan teknik pengumpulan data melalui (a)observasi, (b)interview, dan (c)dokumentasi. Kemudian analisis data dilakukan diawal penelitian sampai kepada akhir kesimpulan. Dari hasil penelitian yang dilakukan diperoleh kesimpulan bahwa: pertama, prinsip penanaman pendidikan multikultural di pondok pesantren Ngalah adalah rahmatan lil'alamin(pengayom bagi semua kalangan). Kedua,Implementasi penanaman pendidikan multikultural di pondok pesantren Ngalah ala NU yang didalamnya mencakup 3 akhlak, yaitu Wathaniyah (Santun terhadap Negara), Insaniyah (Santun terhadap sesama manusia), dan Islamiyah (santun kepada sesama muslim)serta berpegang teguh pada pancasila dan UUD 1945, melalui pembiasaan sikap antara lain :a)Religius(keagamaan), b)Humanis (kemanusiaan), c)Nasionalis,

d) demokrasi e) toleransi. Dengan media teladan pengasuh, orientasi santri baru, ta'lim ad diniyah, kehidupan asrama, pentas seni dan halaqoh. Dibuktikan dengan sikap antusias dan istiqomah santri dalam mengikuti kegiatan pesantren yang sudah terjadwal mulai harian, mingguan, bulanan dan tahunan.

Kata Kunci: penanaman, pendidikan multikultural

\section{PENDAHULUAN}

Pesantren merupakan jenis institusi pendidikan Islam tertua dan telah lama berakar di dalam budaya masyarakat Indonesia. Pesantren merupakan pusat pengkajian dan pendalaman khazanah ilmu-ilmu keislaman dan sekaligus sebagai pusat gerakan dakwah penyebaran agama Islam di masyarakat. Pondok pesantren merupakan lembaga pendidikan yang unik, tidak saja karena keberadaanya yang sudah sangat lama, tetapi juga karena kultur, metode, dan jaringan yang diterapkan oleh lembaga agama tersebut. ${ }^{1}$ Pesantren sebagai salah satu lembaga pendidikan yang menekankan

\footnotetext{
${ }^{1}$ Syafruddin Amir, Pesantren Pembangkit Moral Bangsa.(Online) diakses tanggal 5 April 2017, http:// www.pikiranrakyat.com/cetak/2006/072006/03/11wacana01.htm-28k-
} 
pemahaman agama sebagai ruh kehidupan umat manusia, menjanjikan potensi yang luar biasa.

Sejak awal kehadirannya beberapa abad yang lalu pondok pesantren sebagai lembaga pendidikan dan dakwah, dipijakkan pada misi utamanya untuk menyebarkan ajaran Islam dan mengembangkan tata kehidupan masyarakat sekitarnya dengan cara membangun tradisi kehidupan yang damai, aman dan mandiri. Pondok pesantren secara doktriner tetap mengembangkan prinsip ukhūwah Islāmīyah, ukhāwah wathanīyah, dan ukhūwah basyarīyah dalam upaya memperkuat bangunan Negara Kesatuan Republik Indonesia (NKRI) sekaligus ikut serta membangun tata kehidupan global yang damai.

Karena itu maka pesantren tampil pula sebagai agen pembudayaan nilai, norma, sekaligus pesan-pesan keagamaan yang sarat dengan harmoni, kerukunan, persatuan dan kedamaian, bahkan para ahli menilai pesantren mempunyai peran yang cukup signifikan dalam melestarikan budaya lokal, termasuk memelihara nilai-nilai dan tatanan sosial yang harmonis disekelilingnya. ${ }^{2}$ Pesantren sangat menjunjung tinggi sikap menghargai, tanpa mempersoalkan asal-usul suku, etnis dan ras. Kurikulum pesantren, baik pesantren modern maupun tradisional, mengajarkan peningkatan wawasan kebangsaan pada santri maupun masyarakat lingkungannya agar mereka dapat hidup bersama dan berdampingan dengan berbagai kelompok masyarakat Indonesia yang plural serta mampu menebarkan rahmat bagi lingkungan. ${ }^{3}$

Dalam upaya penanaman pendidikan multikultural, Pondok Pesantren Ngalah memiliki prinsip "rahmatan lil alamin". Prinsip ini dimaksudkan untuk merangkul semua golongan dan tidak membeda-bedakan terhadap latar belakang santri yang ingin mencari ilmu di Pondok Pesantren Ngalah. kemudian tertuang dalam kurikulum Pondok Pesantren Ngalah yang diaplikasikan lewat pengajian/kajian kitab-kitab kuning klasik maupun kontemporer, yang kemudian hasil pembelajaran kajian-kajian tersebut para santri mengimplementasikan dalam kehidupan sehari-hari di pesantren dan sebagai bekal ketika sudah pulang kerumah masing-masing.

Dalam proses penanaman pendidikan multikultural dilingkungan Pondok Pesantren Ngalah yakni dengan melalui pembiasaan dalam mengikuti

\footnotetext{
${ }^{2}$ Nunu Ahmad an-Nahidil. "Pesantren dan Dinamika Pesan Damai" dalam Edukasi, Jurnal Penelitian Agama dan Keagamaan, Vol.4 No.3 ( Jakarta: Puslitbang Pendidikan Agama dan Keagamaan, Badan Litbang dan Diklat Departemen Agama RI, 2006), 18

${ }^{3}$ Sholihuddin. Pesantren dan Budaya Damai, diakses tgl 12 Mei 2013. http://www.gpansor.org/?p=13308,
} 
Pondok Pesantren Ngalah Sengonagung.

semua kegiatan santri mulai dari kegiatan harian, mingguan, bulanan sampai tahunan dengan berbagai media seperti, teladan K.H Sholeh Bahruddin melalui nasihat-nasihatnya, media OSABA \{Orientasi Santri Baru\}, media ta'lim diniyah, kehidupan asrama, pentas seni budaya dan halaqoh. Sebagai bukti keberhasilan pesantren Ngalah dalam mengantarkan para santrinya untuk kesiapan hidup ditengah-tengah masyarakat yang semakin modern, alumni pesantren Ngalah bisa diterima disemua kalangan, ada yang menjadi dokter, bidan, polwan, polisi, TNI, guru, pengusaha, dll. ${ }^{4}$

\section{PEMBAHASAN}

\section{Pendidikan Multikultural}

Paradigma multikultural ini dibawa ke ranah pendidikan, yang kemudian memunculkan istilah pendidikan multikultural, dengan pengertian :

1. Definisi menurut Azyumardi Azra, bahwa Multikulturalisme" pada dasarnya adalah pandangan dunia yang kemudian dapat diterjemahkan ke dalam berbagai kebijakan kebudayaan yang menekankan penerimaan realitas pluralitas agama dan multikultural yang terdapat dalam kehidupan masyarakat. Multikulturalisme juga dapat dipahami sebagai pandangan dunia yang kemudian diwujudkan dalam kesadaran politik

2. Ainurrofiq Dawam mengungkapkan bahwa pendidikan multikultural adalah suatu proses yang berkesinambungan dalam upaya mengembangkan potensi dan ketrampilan yang dimiliki manusia dengan cara menghargai heterogenitas dan pluralitas sebagai sebuah konsekuensi akan adanya keberagaman suku, etnis, budaya maupun aliran (agama) ${ }^{5}$.

Tabel 1

Indikator Nilai-nilai Pendidikan Multikultural ${ }^{6}$

\begin{tabular}{|l|l|l|}
\hline No. & $\begin{array}{c}\text { Nilai-nilai Pendidikan } \\
\text { Multikultural }\end{array}$ & \multicolumn{1}{c|}{ Indikator } \\
\hline 1 & Nilai Toleransi & $\begin{array}{l}\text { Sikap menghargai, membiarkan, atau } \\
\text { membolehkan pendirian (pandangan, } \\
\text { pendapat, kepercayaan, kebiasaan, dan }\end{array}$ \\
\hline
\end{tabular}

\footnotetext{
${ }^{4}$ Ustadz H.Yaqut Nafis. Wawancara Tanggal 20 Juli 2018.

${ }^{5}$ Royen. Diposting pada 3 Oktober 20173.876 views. Pengertian pendidikan multicultural dan berbagai contohnya di akses 10 Agustus 2018 http://www.eventzero.org/pendidikanmultikultural-dan-contohnyal

${ }^{6}$ Salmiwati, Urgensi Pendidikan Agama Islam,... 338
} 
Sifaul Jannah, Muhammad Nur Hadi .:. 31

\begin{tabular}{|l|l|l|}
\hline 2 & Nilai Demokrasi & $\begin{array}{l}\text { sebagainya } \\
\text { Kebebasan dalam memilih profesi, } \\
\text { memilih minat, bahkan dalam } \\
\text { menentukan pilihan agama pun tidak } \\
\text { dapat dipaksa. }\end{array}$ \\
\hline 3 & Nilai kesetaraan & $\begin{array}{l}\text { Sama tingkatan (kedudukan, pangkat), } \\
\text { menunjukkan adanya tingkatan yang } \\
\text { sama, tidak lebih tinggi atau lebih rendah } \\
\text { antara satu sama lain. }\end{array}$ \\
\hline 4 & Nilai Keadilan & $\begin{array}{l}\text { Keseimbangan atau keharmoniasan } \\
\text { antara menuntut hak dan menjalankan } \\
\text { kewajiban. }\end{array}$ \\
\hline
\end{tabular}

\section{Penanaman Pendidikan Multikultural}

Penanaman berasal dari kata tanam yang artinya menaruh, menaburkan, (paham, ajaran, dan sebagainya), memasukan, membangkitkan, atau memelihara (perasaan, cinta kasih, semangat, dan sebagainya). Sedangkan penanaman itu sendiri berarti proses atau caranya, perbuatan menanamkan. ${ }^{7}$

Chabib Thoha dalam bukunya Kapita Selekta Pendidikan Islam, menjelaskan bahwa penanaman adalah suatu tindakan, perilaku atau proses menanamkan suatu tipe kepercayaan yang berada dalam ruang lingkup sistem kepercayaan dimana seseorang bertindak atau menghindari suatu tindakan, atau mengenai sesuatu yang pantas atau tidak pantas dikerjakan. ${ }^{8}$

Dalam proses penanaman, maka tidak akan lepas dari strategi yang akan dipakai dalam upaya keberhasilan. Menurut Sanjaya strategi berarti pola umum aktivitas gutu dan peserta didik dalam perwujudan kegiatan belajar mengajar. ${ }^{9}$ Sebagai perencanaan, adapun kaitan dengan tujuan penanaman pendidikan multikultural menurut pendapat Ramayulis terdapat tujuh pendekatan, antara lain, 1.] Pendekatan pengalaman, 2.]Pembiasaan, 3.]Emosional, 4.] Rasional,5.]fungsional, 6]keteladanan, 7.]pendekatan terpadu.

Upaya penanaman Pendidikan multikultural ini dapat diterapkan dalam suatu lembaga pendidikan formal atau non formal dengan memperhatikan sistem-sistem yang ada dengan melibatkan semua komponen yang ada di dalam lembaga itu harus diarahkan pada konsep pendidikan

\footnotetext{
${ }^{7}$ Qanita Alya. Kamus Indonesia, PT. Indah Jaya Adipratama April 2011. 768

${ }^{8}$ Chabib Thoha, Kapita Selekta Pendidikan Islam, (Yogyakarta : Pustaka Pelajar,2000), 61

${ }^{9}$ Hamruni, Startegi pembelajaran (Yogyakarta:Insan Madani 2012), 1-2
} 
32 .:. Penanaman Pendidikan Multikultural Dalam Membentuk Akhlak Santri Di

Pondok Pesantren Ngalah Sengonagung.

multikultural, seperti nilai-nilai demokrasi, keadilan, kesetraan dan sebaginya yang mencerminkan sikap multikultural.

\section{Pembentukan Akhlak}

\section{Pengertian Akhlak}

Definisi akhlak menurut beberapa tokoh, antara lain :

1. Menurut Imam Ghazali: "akhlak adalah sifat yang tertanam dalam jiwa yang menimbulkan macam-macam perbuatan dengan mudah tanpa memerlukan pemikiran dan pertimbangan lagi".

2. Di dalam Ensiklopedi pendidikan dikatakan akhlak ialah: "budi pekerti, watak kesusilaan (kesadaran etik dan moral) yaitu kelakuan baik yang merupakan akibat dari sikap jiwa yang benar terhadap kholiqnya dan terhadap sesama manusia".

Dari pengertian diatas, maka dapat dipahami bahwa akhlak adalah tabiat atau sifat seseorang, yakni keadaan jiwa yang terlatih, sehingga dalam jiwa tersebut benar-benar telah melekat sifat-sifat yang melahirkan perbuatan dengan mudah dan spontan tanpa dipikirkan dan diangan-angan lagi.

\section{Pembentukan Akhlak}

Pembentukan akhlak ini dilakukan berdasarkan asumsi bahwa akhlak adalah hasil usaha pendidikan, latihan, usaha keras dan pembinaan \{mukhtasabah\}, bukan terjadi dengan sendirinya. Potensi rohaniah yang ada dalam diri manusia termasuk didalamnya akal dan nafsu dibina secara optimal dengan cara pendekatan yang tepat. Akan tetapi sebagian menurut ahli bahwa akhlak tidak perlu dibentuk karena akhlak adalah insting yang dibawah manusia sejak lahir. ${ }^{10}$

\section{Prinsip Penanaman Pendidikan Multikultural di Pesantren Ngalah}

Dalam mewujudkan santri yang memiliki pendidikan multikultural Pengasuh bersama para pengurus Yayasan dan pengurus pondok menggunakan prinsip rahmatan lil alamin. Prinsip rahmatan lil'alamin ini amat penting. Karena bagaimana pun juga saat ini di beberapa tempat, Islam ditampilkan dalam wajah-wajahnya yang keras, ekstrim dan tidak toleran. Sementara itu, ajaran Islam yang hendak ditanamkan dipesantren Ngalah adalah ajaran Islam yang lembut, terbuka dan toleran terhadap sesama, Islam yang benar-benar membawa rahmat untuk semesta alam. Artinya, bahwa pesantren Ngalah tidak memaksakan siapa pun untuk menerima Islam sebagai agama, termasuk menerima ideologi keagamaan Nahdlatul Ulama, melainkan ingin agar nilai-nilai luhur yang ada dalam Islam itu dilaksanakan

${ }^{10}$ Drs.H.A.Mustofa, Akhlak Tasawuf, CV.Pustaka Setia Bandung cet.3 2005, 82-87 
dan dapat memberikan manfaat tidak hanya kepada orang Islam saja, melainkan kepada semua manusia, bahkan kepada sekalian alam.

\section{Implementasi Penanaman Pendidikan Multikultural di Pesantren Ngalah}

Kurikulum Pesantren Ngalah yang secara khusus menyatakan implementasi pendidikan multikultural memang belum ada. Namun kalau diperhatikan dengan seksama, sebenarnya nilai-nilai Islam ahl al-sunnah wa al-jamaah yang ditanamkan di Pesantren Ngalah itu sangat sejalan dengan pendidikan multikultural. Begitu juga dengan kurikulum yang diterapkan semuanya mengandung pendidikan multikultural. Salah satu contoh adalah anjuran dari sang Kyai bahwa santri harus memiliki wawasan ilmu pengetahuan agama maupun umum untuk meraih kebahagiaan dunia akhirat. ${ }^{11}$ Santri harus mampu mempelajari, memahami, dan menguasai ilmuilmu agama yang pokok meliputi: tauhid (kalam), akhlak, syari'ah (fiqh), alQur'an, al-Hadis, sebagai pedoman dalam menjalani kehidupan sehari-hari.

Di samping penguasaan terhadap ilmu-ilmu agama, santri harus mempelajari, memahami, dan menguasai ilmu umum dalam rangka memperjuangkan kepentingan Islam. Di era globalisasi ini, sains dan teknologi informasi maupun komunikasi menempati pada posisi yang vital, oleh karena itu penguasaan pada teknologi informasi dan komunikasi sangat dibutuhkan.

Berdasar pada hasil observasi peneliti pada tanggal 21 Juli 2018, bahwa pesantren Ngalah yang diasuh oleh K.H Sholeh Bahruddin dalam menerapkan pendidikan multikultural berangkat dari prinsip rahmatan lil alamin yakni dengan menerapkan tradisi NU yang didalamnya mencakup 3 akhlak, yaitu Ukhuwah Wathaniyah \{Santun terhadap Negara\}, ukhuwah Insaniyah \{Santun terhadap sesama manusia\}, ukhuwah Islamiyah \{ santun kepada sesama muslim $\}$ serta berpegang teguh pada pancasila dan UUD $1945^{12}$. Adapun pendidikan multikultural dipesantren Ngalah ditanamkan melalui pembiasaan-pembiasaan dalam kehidupan sehari-hari santri, antara lain sebagai berikut :

\section{Nasionalis}

\footnotetext{
${ }^{11}$ Ahmad Muhtaddin, mutiara Nasihat Romo K.H Sholeh Bahruddin Untuk Santri-santrinya, 2010. 14

12 Ahmad Muhtadin, Mutiara Nasihat Romo Kyai Muhammad Sholeh Bahruddin untuk Santri-santrinya Juli 2010. 2
} 
34 .:. Penanaman Pendidikan Multikultural Dalam Membentuk Akhlak Santri Di

Pondok Pesantren Ngalah Sengonagung.

Interview dengan kepala pusat pesantren Ngalah menjelaskan beberapa kegiatan yang nampak sebagai penanaman jiwa nasionalis pada santri adalah: 13

a. Materi kebangsaan saat OSABA (Orientasi Santri Baru)

b. Kegiatan maulid Nabi Muhammad s.a.w dengan tema bersholawat bersama TNI dan POLRI disertai dengan penandatanganan prasasti perdamaian Dunia,

c. Kegiatan seminar kebangsaan

d. Do'a bersama untuk keselamatan Negara

e. Pemasangan Bendera Merah Putih disetiap asrama pada saat 17 Agustus

Berdasakan dawuh romo Kyai.

"Darut Taqwa berwawasan Rahmatan lil alamiin dan berasaskan Pancasila selama-lamanya (K.H Bahruddin, 1977). Dengan tujuan,

1. Agar tidak lupa dengan rumah sendiri

2. Agar tidak berjalan ditempat

3. Agar mempunyai wawasan yang luwas dan luwes

Pondok Pesantren Ngalah berbeda dengan yang lain. Karena didalamnya ada bimbingan thariqah, diantara kewajibannya adalah mbagusi kabeh konco\{berbuat baik dengan semua kalangan\} yang menjunjung tinggi nilainilai perikemanusiaan dan wawasan kebangsaan ${ }^{14}$

\section{Demokratis}

Berdasarkan hasil observasi bahwa penanaman sikap demokratis pada santri tercermin diberbagai kegiatan, ${ }^{15}$ antara lain :

1. Kebebasan semua santri dalam pemilihan kegiatan ekstra yang sifatnya tidak wajib, maka santri bisa memilih sesuai bakat dan minatnya.

2. Kegiatan musyawarah rutin ditingkat pengurus pusat, asrama dan kamar untuk melaksanakan kegiatan dan evaluasi tiap bulan

3. Kebebasan santri dalam memilih profesi dan selalu mendapat od'a restu dari pengasuh.

4. K.H Sholeh Bahruddin memperbolehkan santrinya ikut berpolitik yang beretika tanpa membatasi partai tertentu.

\footnotetext{
${ }^{13}$ Ust. Abd. Ghafur, Kepala pusat pesantren Ngalah (interview 21 Juli 2018)

${ }^{14}$ Buku pedoman santri dalam berbangsa dan bernegara cermin muslim ala Indonesia, agustus 2007, 9

${ }^{15}$ Ust. Abd.Ghofur, M.PdI (interview 21 Juli 2018)
} 


\section{Humanis}

Berdasarkan hasil interview, implementasi pendidikan multikultural di pesantren Ngalah pada sikap humanis adalah:

1. Menganjurkan santri teposeliro marang liyo, yakni anjuran untuk saling menghormati, mengenal, hidup rukun saling mengasihi antar sesama.

2. Membiasakan bersikap adil, sebagai contoh setiap santri yang melanggar peraturan pesantren akan mendapatkan hukuman sebagai proses pendidikan.

3. Kesetaraan, yakni semua santri mendapat fasilitas yang sama tanpa ada diskriminasi.

4. Saling menghargai, dengan mengistilahkan memanusiakan manusia, sebagaimana dawuh K.H Sholeh Bahruddin dalam setiap kegiatan

“Santriku kabeh awakmu nek iso gembul wong tak acungi jempol siji, tapi nek iso ngewongno wong tak acungi jempol loro"16.

Semua santri yang bisa hidup bersama dengan semua orang akan mendapat satu acungan jempol dari sang Kyai dan ketika bisa memanusiakan manusia akan mendapat dua acungan jempol.

sebagaimana nasihat beliau dalam setiap kesempatan,

“ Aku \{Romo Kyai\} paling gak seneng lek onok santri nglakoni perkoro loro, yoiku tukaran sak konco \{berkelahi sesama teman\} lan pacaran. $^{17}$

"K.H Sholeh Bahruddin akan merasa tidak suka ketika santrinya melakukan 2 hal, yaitu berkelahi sesama teman dan berhubungan ghoiru muhrim.

Sebagai bukti penanaman sikap humanis pada santri, pesantren Ngalah sering di jadikan pusat kegiatan dan kajian muslim maupun non muslim antara lain :

1. Acara IDAROH Jam'yah ahli thoriqoh al-mu'tabaroh an-nahdliyah yakni musyawaroh idaroh wustho se-Jawa Timur, dialog dengan tamu Italia untuk Islam Nusantara

${ }^{16}$ Ahmad Muhtadin, Mutiara Nasihat Romo Kyai Muhammad Sholeh Bahruddin untuk Santri-santrinya Juli 2010

17 Ahmad Muhtadin, Mutiara Nasihat Romo Kyai Muhammad Sholeh Bahruddin untuk Santri-santrinya Juli 2010, 2 
36 .:. Penanaman Pendidikan Multikultural Dalam Membentuk Akhlak Santri Di

Pondok Pesantren Ngalah Sengonagung.

2. Seminar nasional kerukunan antar ummat beragama, kunjungan dari warga Papua, kelompok pemuda GKJW dalam rangka dialog kebangsaan dengan lintas agama

3. Tamu Luar Negeri Germany live in Ngalah,

4. Seniman baik dari dalam kota, luar kota dan ibu kota

5. Kegiatan rutin senin, selasa, kamis malam dan ahad dzikurl ghofilin dengan warga sekitar

6. Pejabat daerah maupun wilayah, sipil maupun non sipil

Nasihat beliau merupakan bukti bahwa penanaman pendidikan multikultural dipesantren Ngalah dalam segala aspek, tidak hanya hubungan sesama muslim akan tetapi dengan siapapun tanpa melihat status agama, ras dan budaya.

\section{Toleransi}

Berdasarkan hasil interview dengan kepala pusat pesantren Ngalah bahwa penanaman sikap toleransi pada santri dalam berbagai hal, antara lain : 18

1. Mengikut sertakan santri dalam acara gelar budaya dengan lintas agama

2. Menghormati semua tamu yang sedang berkunjung kepesantren

3. Hidup berdampingan dalam perbedaan dengan rukun dipesantren

4. Mengantar atau menjenguk santri yang sakit atau takziyah pada keluarga santri yang mengalami musibah

5. Saling berkunjung antar kamar untuk silaturrahmi dan meminta maaf ketika malam jumat

6. Mendamaikan santri yang sedang berselisih.

sebagaimana dawuh sang maha guru.

"Agomo ngono ora dek ator fiqih tok lho le, tashowuf yho melu ngatur, soale rukune agomo iku ono telu,yaoiku iman, islam lan ikhsan. Ikhsan yoiku berbuat baik marang kabeh makhluk, gak pandang apik utowo elek, bah sembahyang gak sembahyang kabeh dibagusi ${ }^{\prime \prime}$.

" Agama tidak diatur ilmu fiqih saja, ilmu tasawuf juga ikut mengatur, Soalnya rukun agama itu ada 3, yaitu iman, islam dan ikhsan, yaitu berbuat baik pada semua makhluk, tidak memandang

\footnotetext{
${ }^{18}$ Ust. Abd. Gahfur, Kepala pusat peantren Ngalah (interview 21 Juli 2018)

19 Ahmad Muhtadin, S.Psi, Mutiara nasihat Romo K.H M.Sholeh Bahruddin untuk santri santrinya, 5
} 
baik atau buruk, yang melaksanakan shalat atau tidak semua harus diperlakukan baik.

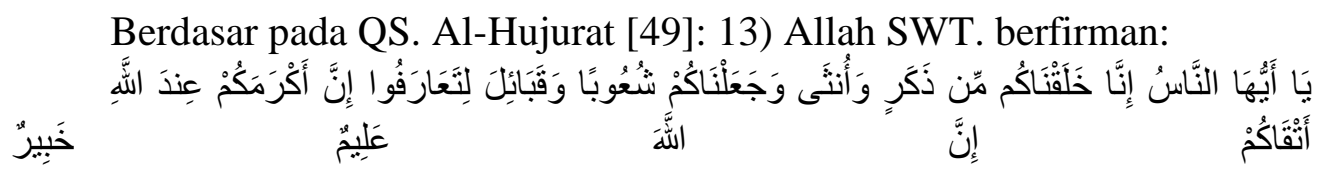

Tersirat bahwa perbedaan yang ada di muka bumi ini memang kehendak Allah SWT., yang dari adanya perbedaan-perbedaan itu manusia dituntut untuk bisa saling mengenal satu sama lain, ${ }^{20}$ yang ini secara tidak langsung mengandung semangat toleransi sebagaimana yang telah disebutkan di atas.

\section{Religius}

Berdasarkan hasil interview beberapa pembiasaan sikap religius yang telah diimplementasikan dalam kehidupan sehari-hari dipesantren Ngalah adalah :

1. Mengawali setiap kegiatan dengan do'a bersama

2. Aplikasi ubudiya di masing-masing asrama

3. Setiap santri mengikuti Madrasatul Qur'an

4. Istiqomah melaksanakan jama'ah sholat malam

5. Mengikuti pengajian kitab tafsir yang dipimpin langsung oleh pengasuh

6. Mengikuti pengajian kitab ta'limul muta'allim

7. Pembacaan yasin, tahlil dan dzikrul ghofilin secara rutin sesuai jadwal

8. Diadakan sholat lailatul qadar setiap tahun bersama warga

Berdasar pada hasil interview, maka penanaman nilai religius dipesantren Ngalah tercermin pada sikap antusias santri, semangat kebersamaan serta keaktifan dan ketertiban santri dalam mengikuti kegiatan yang diadakan harian, mingguan, bulanan bahkan tahunan. Dan diperkuat dengan hasil dokumentasi

\section{KESIMPULAN}

Berdasarkan hasil penelitian yang telah dilakukan melalui analisis data yang telah di dapatkan dari hasil observasi, interview, dokumentasi dan datadata yang mendukung penelitian ini, maka pada akhirnya peneliti dapat mengambil kesimpulan sebagai berikut:

${ }^{20}$ Departemen Agama RI, Al-Qur'an dan Terjemah juz 1-30, Karya Agung Surabaya edisi terbaru, 468 
38 .:. Penanaman Pendidikan Multikultural Dalam Membentuk Akhlak Santri Di

Pondok Pesantren Ngalah Sengonagung.

1. Prinsip penanaman pendidikan multikultural di pondok pesantren Ngalah adalah rahmatan lil'alamin \{melindungi semua kalangan, sejalan dengan apa yang termaktub dalam (QS al-anbiya' 21:107). وَمَا أَرْسَلْناكَ إِلَّ رَحْمَةً للِعحالَمِينَ

"Kami tidak mengutus engkau, Wahai Muhammad, melainkan sebagai rahmat bagi seluruh manusia" (QS. Al Anbiya: 107)

2. Implementasi pendidikan multikultural di pesantren Ngalah sebagaimana prinsip NU, yakni Insaniyah/Basyariyah \{Santun terhadap sesama manusia\}, Wathaniyah \{santun terhadap negara\}, Islamiyah \{Santun terhadap sesama Muslim\}, diwujudkan dalam bentuk pembiasaan sikap berikut :

Pertama sikap Humanis, yakni melalui pembiasaan santri bersikap teposeliro marang wong liyo, yakni menghormati kepada yang lain, membiasakan bersikap adil, dan Saling menghargai dengan di libatkan secara langsung seperti kegiatan MUSDAH Thariqah se Jawa Timur, dilaog lintas agama, menerima sharing pendidikan dengan warga Papua dan Singapore, kelompok seniman, para pejabat dan warga sekitar.

Kedua sikap nasionalis, yakni pemberian bekal kepada para santri agar santri merasa memiliki bangsa Indonesia dan berkewajiban untuk mempertahankan kemerdekaannya melalui beberapa kegiatan, antara lain memberikan materi kebangsaan saat OSABA \{Orientasi Santri Baru\}, penandatanganan prasasti perdamaian Dunia bersama TNI dan POLRI, Kegiatan seminar kebangsaan dengan lintas agama, do'a bersama untuk keselamatan Bangsa dan Negara, kegiatan lomba dalam rangka memeperingati kemerdekaan RI dan melaksanakan upacara bendera serta do'a untuk para pahlawan juga pemasangan Bendera Merah Putih pada saat 17 Agustus.

Ketiga sikap Demokratis, yakni melalui tauladan pengasuh dan pengurus serta pembiasaan-pembiasaan seperti kebebasan semua santri dalam pemilihan kegiatan ekstra, pemilihan kamar walaupun pengurus sudah menyiapkan sesuai tingkat pendidikan formalnya, akan tetapi pengurus memberi kebebasan kepada calon santri untuk memilih dengan tujuan agar santri merasa nyaman dan krasan, keikut sertaan santri dalam memberikan hak pilihnya di PEMILU, kegiatan musyawarah rutin ditingkat pengurus pusat, asrama dan kamar untuk melaksanakan kegiatan dan evaluasi tiap bulan, kebebasan santri dalam memilih profesi setelah lulus dari pesantren dan selalu mendapat do'a restu dari pengasuh, K.H Sholeh 
Bahruddin memperbolehkan santrinya ikut berpolitik yang beretika tanpa membatasi partai tertentu, agar santri bisa hidup bersama dengan siapapun Keempat sikap Toleransi, seperti santri yang muda menghormati santri yang lebih tua. Junior menghargai dan ingin meneladani kebaikan dan kesuksesan senior. Sementara senior mengasihi dan membimbing junior. Dalam kegiatan peantren seperti menghormati semua tamu dari segala kalangan dan semua agama. Seperti tamu dari GKJW

Kelima sikap Religius, yakni melalui pembiasaan-pembiasaan santri bersikap didalam pesantren seperti membiasakan sholat berjamaah, membiasakan mengucapkan salam dan menjawab salam, membaca hafalan bacaan yang di wajibkan, dan mengawali do'a dalam setiap kegiatan kemudian mengintegrasikan kedalam kehidupan sehari-hari bahwa agama merupakan kunci menjalankan suatu kehidupan.

Dalam proses penanaman pendidikan multikultural, pesantren Ngalah menggunakan berbagai media yang mampu memberikan kontribusi sebagai jalan menanamkan pendidikan multikultural dalam dinamika kehidupan santri yang majemuk, sehingga dapat membentuk akhlak mulia para santri. Media tersebut antara lain :teladan pengasuh, orientasi Santri Baru $\{\mathrm{OSABA}\}$, ta'lim al diniyah \{Madrasah diniyah\}, kehidupan asrama, pentas seni dam halaqoh.

\section{DAFTAR PUSTAKA}

Aris Kurniawan. Diposting pada 27/08/2018. Pengertian pendidikan multicultural menurut beberapa ahli Di akses 14 Oktober 2018 https://www.gurupendidikan.co.id/9-pengertian-multikultural-menurutpara-ahli/

Chabib Thoha, Kapita Selekta Pendidikan Islam, (Yogyakarta : Pustaka Pelajar,2000), 61

Drs.H.A.Mustofa, Akhlak Tasawuf, CV.Pustaka Setia Bandung cet.3 2005, $82-87$

Erna Widodo dan Mukhtar, Kontruksi Kearah Penelitian Deskriptif (Yogyakarta: Avyrouz, 2000), 7.

Hamruni, Startegi pembelajaran (Yogyakarta:Insan Madani 2012), 1-2 John A Titaley. Beberapa Model Keragaman Agama di Asia: Keunikan Kehidupan Beragama di Indonesia, (Yogyakarta: Oasis Publisher, 2005), 117. 
40 :.: Penanaman Pendidikan Multikultural Dalam Membentuk Akhlak Santri Di

Pondok Pesantren Ngalah Sengonagung.

Nunu Ahmad an-Nahidil. "Pesantren dan Dinamika Pesan Damai" dalam Edukasi, Jurnal Penelitian Agama dan Keagamaan, Vol.4 No.3 ( Jakarta: Puslitbang Pendidikan Agama dan Keagamaan, Badan Litbang dan Diklat Departemen Agama RI, 2006), 18

Royen. Diposting pada 3 Oktober 20173.876 views. Pengertian pendidikan multicultural dan berbagai contohnya di akses 10 Agustus 2018 http://www.eventzero.org/pendidikan-multikultural-dan-contohnyal

Rahmi Fhonna, Internalisasi Nilai-nilai Multikultural, (Banda Aceh: YAB, 2011), 34.

Syafruddin Amir, Pesantren Pembangkit Moral Bangsa.(Online) diakses tanggal

5April2017,http://www.pikiranrakyat.com/cetak/2006/072006/0 3/11wacana01.htm-28k-

Sholihuddin. Pesantren dan Budaya Damai, diakses tgl 12 Mei 2013. http://www.gp- ansor.org/?p=13308,

Salmiwati, Urgensi Pendidikan Agama Islam,... 338

Qanita Alya. Kamus Indonesia, PT. Indah Jaya Adipratama April 2011. 768

Pedoman Pengurus pesantren Ngalah periode 2015-2020 Dokumen profil pesantren 2018 